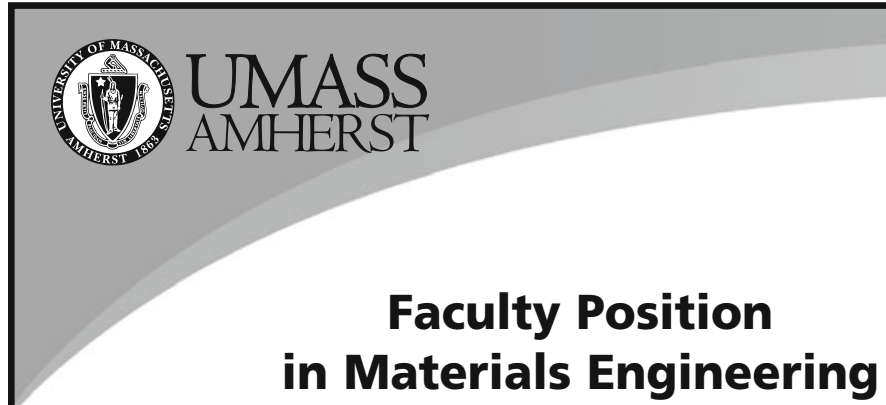

The Department of Mechanical and Industrial Engineering (MIE) at the University of Massachusetts Amherst invites applications for a tenure track position in the area of materials engineering. The appointment is at the rank of assistant, associate or full professor. Faculty members are expected to teach both undergraduate and graduate courses, supervise graduate students and postdoctoral fellows, contribute significantly to the advance of basic science and engineering as evidenced by scholarly publications, and develop a nationally recognized program of sponsored research. Applicants specializing in an approach consistent with the Materials Genome Initiative ${ }^{1}$ through computational or experimental methods, and those with research applicable to biomaterials and energy materials are especially encouraged. In addition, where appropriate, the new faculty will participate in the development of new graduate programs within the College of Engineering.

The Department of Mechanical and Industrial Engineering has 25 full-time faculty members, over 130 graduate students, and over 650 undergraduates. Research expenditures exceeded $\$ 4.7 \mathrm{M}$ in the last fiscal year. A number of institutes and centers provide outstanding opportunities for faculty, including the Pioneer Valley Life Sciences Institute, the Institute of Cellular Engineering, Baystate Medical Center, the University of Massachusetts Medical School, the Center on Polymer-Based Materials for Harvesting Solar Energy, the Energy Frontier Research Center, NSF Center for Hierarchical Manufacturing, NSF Materials Research Science and Engineering Center, the NSF Center for e-Design, the Institute for Massachusetts Biofuels Research, the Center for Energy Efficiency and Renewable Energy, and the Wind Energy Center. In addition, the Department has an NSF IGERT in wind energy which will fund 24 doctoral students over 5 years.

The University of Massachusetts is situated 90 miles west of Boston in the vicinity of four liberal arts colleges offering exceptional and diverse cultural and recreational opportunities.

Minimum Qualifications: Applicants must have a PhD in materials science, mechanical engineering, or a closely related field (degree by September, 2013).

To apply, candidates should provide the following in their application package: 1 ) Statement of interest, teaching and research qualifications, description of research goals, and a discussion of how the candidate's experience would add to existing departmental and university strengths. 2) Current curriculum vitae. 3) Representative recent original research articles. 4) Full contact information for at least four references. Review of applications will begin immediately and continue until a suitable candidate is identified. Applications should be submitted via email in single PDF file: miedept@ecs.umass.edu.

The University of Massachusetts Amberst is an Affirmative Action/Equal Opportunity Employer. The Department, College, and University have a strong commitment to diversity. Women and members of minority groups are encouraged to apply.

${ }^{1}$ http://www.whitehouse.gov/sites/default/files/microsites/ostp/materials_genome_ initiative-final.pdf

\title{
A FULL-TIME, TENURE-TRACK
} FACULTY POSITION

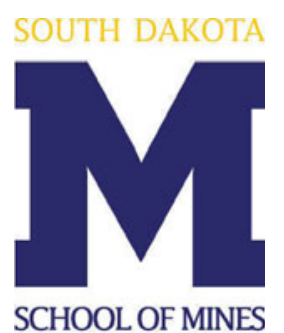

\& TECHNOLOGY
A full-time, tenure-track faculty position at the Assistant, Associate or Professor level is available in the Department of Materials and Metallurgical Engineering at the South Dakota School of Mines \& Technology. A $\mathrm{PhD}$ in Metallurgical Engineering, or closely related field is required; additional education and/or experience in Biomaterials are preferred. The successful candidate will teach undergraduate and graduate courses, including physical metallurgy, mechanical metallurgy, bioengineering-related courses and initiate and/or sustain strong sponsored research and graduate education programs. The department leads the MS and PhD Materials Engineering and Science interdisciplinary graduate program and participates in the MS and PhD Biomedical Engineering interdisciplinary graduate program. The successful candidate is expected to develop a research program supporting both of these graduate programs.

Individuals interested in this position must apply online at http://www. sdsmt.edu/employment. Human Resources can provide accommodation to the online application process and may be reached at (605) 394-1203. Review of applications will begin on January 22, 2013, and will continue until the position is filled. Employment is contingent upon completion of a satisfactory background investigation. This position is funded from general funds and is needed to support the undergraduate and graduate educational and research missions of the university.

SDSM\&T is an EEO/AA/ADA employer \& provider

\section{TENURE-TRACK FACULTY POSITIONS}

\section{DSI Oregon State}

The School of Mechanical, Industrial, and Manufacturing Engineering at Oregon State University invites applications for multiple tenure-track faculty positions in the broad area of Materials Science with a specific focus on Metallurgy. The appointment will nominally be made at the Assistant Professor level, though appointments at the Associate or Full Professor level will be considered depending on the qualifications of the applicant. Preference will be given to candidates with strong research and teaching experience in the areas of mechanical and physical metallurgy, advanced metal alloys, materials processing, and materials performance. To review posting and apply, go to http://oregonstate.edu/ jobs. For full consideration, apply by January 31, 2013. Closing date is 02/10/13. Apply online with a letter of interest; vita; a two-page statement of research interests; a one-page statement of teaching interests; and names and contact information for four references. OSU is an AA/EOE. 


\section{MATERIALS RESOURCE CENTER: Positions Available}

TENURE-TRACK POSITIONS IN MATERIALS SCIENCE AND ENGINEERING

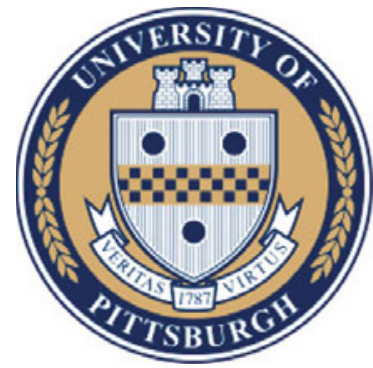
applications
The Department of Mechanical Engineering and Materials Science (MEMS) at the University of Pittsburgh (Pitt) invites applications for two tenure $\neg$ track positions in Materials Science and Engineering (MSE). Successful applicants are expected to build an externally funded research program which contributes to the existing strengths of our program while enhancing strategic areas targeted for future growth, such as advanced processing with particular focus on additive manufacturing and energy,

Applicants should also have a sound background for and dedication to teaching undergraduate and graduate courses in the Materials Science and Engineering programs. Accordingly, applicants should have a Ph.D. in Materials Science \& Engineering or a related field, and a demonstrated commitment to excellence in teaching and research. While the position is primarily for the junior rank, applicants with outstanding track records of higher ranks will also be considered. Although, preference will be given to applicants whose research focus is Physical Materials (Physical Metallurgy, Physical Ceramics), exceptional candidates in our strategic areas of growth are encouraged to apply.

The Department of Mechanical Engineering and Materials Science, formed by a merger of the departments of Mechanical Engineering and Materials Science and Engineering in 2006, has 28 tenured or tenure-track faculty members who generate nearly $\$ 7$ million in annual research expenditures.

Current research thrusts include high temperature materials, materials processing, computational mechanics and fluid dynamics, computational materials science, material characterization at multiple length scales, energy technologies, smart materials and structures, functional nanomaterials, micro/biofluidics, biomaterials, advanced ceramics, smart structures, and biomechanics.

The successful candidates for this position will especially benefit from the resources, support, and multidisciplinary research environment fostered by the University of Pittsburgh's Center for Simulation and Modeling (http://www.sam.pitt.edu), the Pittsburgh Supercomputing Center (http://www.psc.edu), and the Center for Energy (http://www.energy.pitt.edu). The Petersen Institute of NanoScience and Engineering's (http://www.nano.pitt.edu) Nanoscale Fabrication and Characterization Facility houses state-of-the-art transmission electron microscopy, dual beam FIB, dedicated E-beam lithography, SEM, EPMA, FTIR, SPM, XRD, UV-Vis-IR spectrophotometer and clean-room facilities.

Qualified applicants are strongly encouraged to submit their application electronically to pitt-mems-search@engr.pitt.edu. Applications should include the following materials in pdf form: a curriculum vitae, a statement of research interests and teaching philosophy, and a list of at least three references. Application can also be submitted by mail to Chair(MSE Faculty Search), Department of Mechanical Engineering and Materials Science, 636 Benedum Hall, Swanson School of Engineering, University of Pittsburgh, Pittsburgh, PA 15261. Review of applications will begin on January 2, 2013, and continue until the positions are filled. Women and minorities are strongly encouraged to apply. The University of Pittsburgh is an equal opportunity/affirmative action employer.

\section{AVAILABLE FACULTY POSITIONS IN METALS AND CERAMICS PROCESSING}

\section{Georgia}

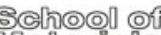

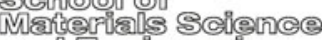
and] [E] College of Engineering

The School of Materials Science and Engineering (MSE) at the Georgia Institute of Technology (GT) is seeking to add tenure-track faculty in the areas of metals and ceramics processing (as described below). While preference will be given to candidates at the Assistant Professor level, applicants with exceptional records of creativity, originality, and excellence will also be considered at the Associate and Full Professor levels. Further details regarding qualifications for these positions can be found at: http://www.mse.gatech. edu/faculty-staff/faculty-positions

Successful candidates will be expected to lead independent research programs at the cutting edge of their field, attract externalfunding to build strong sponsoredresearch activities, successfully mentor graduate students, and develop and teach metallurgy or ceramics courses at the undergraduate and graduate levels. There are numerous opportunities for campus-wide interactions with the various academic units in the Colleges of Engineering and Science, as well as with interdisciplinary institutes, such as the Institute for Materials, the Manufacturing Institute, and the Strategic Energy Institute.

Interested candidates must submit an online application, which includes a cover letter, curriculum vitae, statements of research interest and teaching philosophy, and the names (and contact information) of at least five references, at: http://www. mse.gatech.edu/faculty-staff/facultypositions. Applications will be considered until the positions are filled. The selection process will include passing a preemployment background screening. Georgia Tech is an Equal Opportunity/ Affirmative Action Employer.
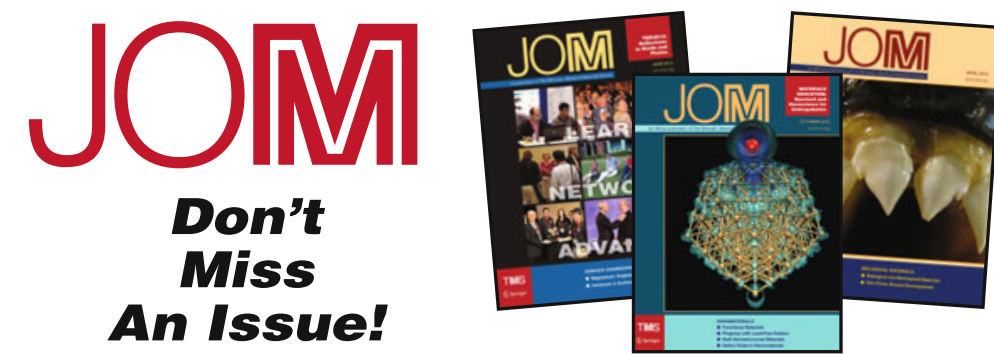

If you have not already done so, renew your TMS membership for 2013.

\section{Visit: members.tms.org}

This will ensure no interruption in receipt of your JOM subscription for 2013.

Remember that your TMS membership includes complete online access to JOM as well, including full-issue archives dating back to 1989

Log in at members.tms.org and renew your membership now for 2013. 


\section{MATERIALS RESOURCE CENTER: Positions Available}

FACULTY POSITION IN THE DEPARTMENT OF APPLIED PHYSICS AND MATERIALS SCIENCE FOCUSED

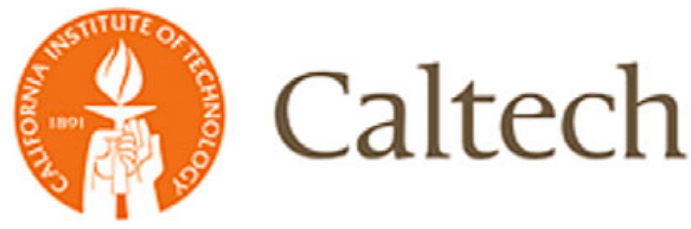

California Institute of Technology

The Department of Applied Physics and Materials Science within the Division of Engineering and Applied Science at Caltech invites applications for a tenure-track position at the assistant professor level. We are seeking highly qualified candidates committed to a career in research and teaching.

In addition to applicants from the traditional areas of materials science and engineering, we are interested in applicants with an interdisciplinary background spanning these and other areas such as computational methods, surface science, nanoscience, and energy science and technology.

Interested applicants should submit an electronic application by visiting http://eas.caltech.edu/positions/apms_ms.

Candidates are required to submit a current $\mathrm{CV}$, research and teaching statements, copies of key publications, as well as three to six letters of reference.Initial appointments at the assistant professor level are for four years and are contingent on completion of the PhD degree.

Caltech is an Equal-Opportunity/Affirmative Action Employer. Women, minorities, veterans, and disabled persons are encouraged to apply.
I'VE SPECIALIZED FOR 33 YEARS

in the placement of Metallurgical, Materials, and Welding Engineers in the areas of R\&D, Q.C. Production, Sales \& Marketing, nationwide. My background as a Met. Eng. can help you! Salaries to \$190K. Fees paid by Co. Call/Send/E-mail Resume:

Michael Heineman, Meta-Find, Inc.; P.O. Box 610525, Bayside, NY, 11361; Phone: (212) 867-8100;

E-mail: mikeh@ meta-findny.com; Web: www.meta-findny.com

\section{Cut through the clutter...use the TMS Marketplace! Everything You Need for One-Stop Shopping...}

- Up to-date inventories from the leading materials suppliers

- Clutter-free searching for quick results

- Downloadable to your desktop for easy access

Visit www.tms.org and select the TMS Marketplace to access the most up-to-date information on vendors who support the metals and materials industries.

\section{FACULTY POSITION - THE UNIVERSITY OF TENNESSEE KNOXVILLE ASSISTANT PROFESSOR - MATERIALS SCIENCE AND ENGINEERING}

The Department of Materials Science and Engineering (MSE) at the University of Tennessee invites applicants for a tenuretrack faculty position at the Assistant Professor Level. The successful candidate will be expected to develop strong externally funded research programs in an area of interest to the department, including, but not limited to: advanced materials synthesis and characterization, materials for advanced energy systems, and computational materials science. These research areas are also emphasized by the nearby (20 miles) Oak Ridge National Laboratory (ORNL), with which the department has strong research interaction. The ORNL facilities that are of special interest include the Center for Nanophase Materials Science (CNMS), the Oak Ridge Leadership Computing Facility (OLCF) and the Spallation Neutron Source (SNS).

Applicants must hold a PhD in Materials Science and Engineering or closely related field and have an established record of excellence in their area of specialization. The successful candidate must be qualified to teach materials science and engineering courses at both the undergraduate and graduate levels. More details about the department can be found at http://www.engr.utk.edu/mse.

The University of Tennessee, Knoxville, is the state's flagship research institution. As a land-grant university, it is committed to excellence in learning, scholarship, and engagement with society. In all its activities, the university aims to advance the frontiers of human knowledge and enrich and elevate society. The MSE Department has a diverse faculty with broad research interests. The University offers world-class research opportunities, including interdisciplinary collaborative research centers: Scintillation Materials Research Center (SMRC), Center for Materials Processing (CMP), Joint Institute for Advanced Materials (JIAM), Joint Institute for Neutron Sciences (JINS), Joint institute for Computational Sciences (JICS).

The Knoxville campus of the University of Tennessee is seeking candidates who have the ability to contribute in meaningful ways to the diversity and intercultural goals of the University. Interested individuals should submit electronically a complete curriculum vitae (no length restriction), a research plan and a summary of teaching interests (2 page maximum each), and the names and contact information (including e-mail addresses) of five potential references to: MSEsearch@utk.edu. Screening will begin around November 1, 2012 and will continue until the position is filled.

The University of Tennessee is an EEO/AA/Title VI/Title IX/Section 504/ADA/ADEA institution in the provision of its education and employment programs and services. All qualified applicants will receive equal consideration for employment without regard to race, color, national origin, religion, sex, pregnancy, marital status, sexual orientation, gender identity, age, physical or mental disability, or covered veteran status. 